\title{
Los microbios interpelan a las terapias
}

\author{
Guillermo Foladori ${ }^{1}$
}

Resumen. El COVID-19 ha sido la causa inmediata de la más profunda crisis de la sociedad moderna. Este artículo trata de un aspecto de esta crisis: el papel de la medicina capitalista hegemónica. El enfoque no es técnico sino social; no se refiere a la eficacia del diagnóstico o sus medicamentos, sino a la trayectoria teórica y metodológica de largo alcance. El objetivo es llamar la atención sobre cómo la medicina capitalista hegemónica ha roto radicalmente con las tradiciones médicas precapitalistas, sin considerar oportunidades en ciencia y tecnología que podrían resultar más eficientes para atender la salud de la población, pero desechadas por seleccionar un camino más rentable para la industria farmacéutica.

Palabras clave: COVID-19, biomedicina, pandemia, virus.

${ }^{1}$ Unidad Académica en Estudios del Desarrollo, Universidad Autónoma de Zacatecas, México.gfoladori@gmail.com 


\section{The germs are demanding new therapies Capitalist medicine is the wrong prescription for modern illnesses}

Abstract. COVID-19 has been the immediate cause of the deepest crisis of modern society. This article deals with one aspect of this crisis: the role of the hegemonic capitalist medicine. The approach is not technical, but social; it does not focus on the efficacy of the diagnosis or its remedies and medications, but on the long-range theoretical and methodological trajectory. The purpose is to draw attention on how hegemonic capitalist medicine has radically broken with precapitalist medical traditions, disregarding opportunities in science and technology that could be more efficient to attend the health of the population, but discarded for selecting a more profitable path for the pharmaceutical industry.

Keywords: COVID-19, biomedicine, pandemic, virus. 


\section{Introducción}

A 10 meses de desatada la pandemia de la COVID-19 hay 1 millón 140 mil muertos acumulados. Se trata de la primera pandemia global provocada por un retrovirus. A pesar que algunos gobiernos e instituciones preveían una pandemia causada por un coronavirus desde hace más de una década, puede decirse que la COVID-19 tomó por sorpresa al mundo entero, debido a la virulencia, rapidez y amplitud con que alcanzó nivel planetario en pocos meses.

Pareciera absurdo que con la tecnología que actualmente se tiene, que permite la secuencia genética y análisis filogenético de un virus en minutos, como de hecho se hizo con el SARS-CoV-2 que dio origen a la pandemia, ${ }^{2}$ junto a sofisticados softwares de procesamiento de datos globales (Big Data), y la posibilidad de monitoreo permanente de condiciones de salud (Grubaugh et al., 2019), no pueda establecerse un sistema mundial eficiente de predicción de epidemias. En los últimos 10 años los medios vienen reportando lo que han denominado la revolución industrial 4.0, siendo que la base de ella es la alta conectividad entre bases de datos, equipos industriales, y sistemas de transporte y comercio. No obstante, todo indica que la industria 4.0 no llegó a la salud pública mundial.

La pandemia ha cuestionado el desarrollo capitalista, y particularmente a muchos de sus sectores económicos, como causantes de las condiciones favorables para que surja la pandemia y cobre tantas víctimas. También el sector salud, en concreto la salud pública, ha sido cuestionada,

${ }^{2}$ El virus fue aislado el 7 de enero de 2020 y su secuencia genética se dio a conocer cinco días después (World Health Organisation, 2020). 
principalmente por el abandono que sufrió en muchos países como resultado de las políticas neoliberales desde la década de 1980. Esas políticas tendieron a privatizar sectores antes públicos y cuando no privatizaron redujeron significativamente el financiamiento, con lo cual la salud pública perdió capacidad de reacción frente a una pandemia novedosa por su alto potencial de contagio, por hacer estragos en la salud de los pacientes, y porque ninguno de los fármacos existentes ha resultado significativamente útil, luego de haberse experimentado con una gran variedad durante tantos meses.

Aunque todas las causas que se adjudican como favorables para la explosión de la pandemia sean ciertas, resta discutir si las principales terapias son efectivas para reducir o impedir la expansión de la pandemia y el surgimiento de otras semejantes. Este artículo trata específicamente de las principales características de la moderna medicina capitalista, señala algunos aspectos que generan dudas sobre la capacidad terapéutica cuando enfrenta a epidemias del calibre de la COVID-19.

Comprende cinco apartados además de esta introducción y las conclusiones. En el segundo se destacan características generales de la COVID-19, su potencial origen y sus probables causas. En el tercero, se realiza una síntesis del desarrollo histórico de la medicina en épocas precapitalistas. Esto es imprescindible para entender el radical cambio que sufre la medicina una vez inmersa en el modo capitalista de producción, que se analizará posteriormente. En el cuarto apartado se muestran los aspectos clave en el cambio de las condiciones de vida bajo relaciones capitalistas y la manera en que ellos, y el bagaje ideológico asociado, cambian el rumbo de la medicina heredada de tiempos pretéritos. Se mencionan también los medicamentos estrella (vacunas y antibióticos) con los que la medicina 
capitalista conquista hegemonía. El quinto individualiza los principales periodos de crisis de la medicina capitalista, como resultado de la pérdida y el cuestionamiento de la efectividad de sus principales medicamentos terapéuticos. De igual modo, se exhiben aquí los mecanismos de carácter político, jurídico y administrativo que el sistema capitalista utiliza para contrarrestar los momentos de crisis y garantizar la hegemonía de su terapia estrella. El sexto apartado establece la conexión de la pandemia de la COVID-19 y su tratamiento con la trayectoria anteriormente analizada. Las conclusiones sintetizan la preocupación principal del artículo.

\section{El triunfo de los microbios y la pandemia de la covid-19}

Transcurridos 10 meses de desatada la pandemia y con un ritmo de más de 5 mil muertos diarios, no se vislumbra un fin. Dependerá más de la retirada de los microbios que de los mecanismos humanos de control.

La pandemia ha puesto en evidencia lo que diversos grupos sociales venían alertando desde hace décadas: el carácter insustentable del desarrollo capitalista. Diversas publicaciones científicas mencionan ejemplos de la conexión entre la COVID-19 y diversos sectores económicos.

Se menciona, por ejemplo, la degradación ambiental, la producción animal confinada, o la agricultura química y de monocultivo, junto a la deforestación como probable causa del surgimiento y expansión de la pandemia (Wallace, 2016). La Organización Mundial de la Salud (OMS) ha reconocido que la COVID-19 está asociada a la destrucción de la naturaleza (Carrington, 2020). 


\section{GUILLERMO FOLADORI}

En efecto, el SARS-CoV-2, que produce la enfermedad COVID-19, es de la familia coronavirus y del género betacoronavirus, y es un virus zoonótico. El virus pertenece al subgénero sarbecovirus, y tiene la mayor afinidad genética (96.2 por ciento) con un coronavirus extendido entre murciélagos. Esta afinidad lleva a considerar que el SARS-CoV-2 puede tener su origen en los murciélagos, transmitido y mutado en otros animales. ${ }^{3}$ Los murciélagos serían el repositorio natural más probable de la variedad más cercana al SARS-CoV-2 (Cheng et al., 2007; Vellingiri et al., 2020); hay estudios que indican que la deforestación, la agricultura y la ganadería de escala son la causa de la expansión de los murciélagos (Afelt et al., 2018).

Otros investigadores ponen el acento en las precarias condiciones de salud de la población, que facilita el contagio y la enfermedad; con su causa en elementos que degradan los ecosistemas y terminan alterando funciones orgánicas, como en el caso de micro y nanopartículas de químicos tóxicos que están en prácticamente todas las cosas de uso cotidiano, y que su degradación termina incorporándose a las diversas cadenas tróficas (Heindel y Birbaum, 2020; IPEN, 2020). Otra causa que podría deteriorar la salud es la expansión de las radiaciones provocadas por el sistema de comunicaciones 5G (Attkisson, 2019; EMFscientist.org, 2017; Ketcham, 2020). También es relevante el hacinamiento en ciudades, la inequidad, el desempleo y la pobreza (Kaufmann et al., 2009); sin descartar otras muchas causas como el aumento del transporte, el movimiento de personas y mercancías en las últimas décadas.

Las correlaciones estadísticas son elocuentes de la relación entre pobreza y desigualdad para explicar el diferente impacto de la enfermedad

${ }^{3}$ Así ha sido, probablemente en el caso de la epidemia de SARS-1 en 2003, con la civeta como intermediario (Paguma larvata) (Cheng et al., 2007). 
en los pacientes. Una investigación de la Harvard School of Public Health para más de 3 mil condados de Estados Unidos establece la correlación entre muertes por el coronavirus y pacientes previamente enfermos por habitar en zonas con una larga historia de contaminación aérea y de pobreza. Destacan en peor situación los afroamericanos, grupo étnico más pobre del país. ${ }^{4}$ En la ciudad de Chicago los afroamericanos representan 30 por ciento de la población; no obstante, en los primeros días de abril de 2020, los muertos por el coronavirus alcanzaron 70 por ciento. En Wisconsin representan 6 por ciento de la población y 40 por ciento los decesos. En el «Cancer Alley» de Luisiana la población tiene 50 por ciento más probabilidades de tener cáncer que el americano medio; una región plagada de refinerías y plantas petroquímicas, donde los afroamericanos (32 por ciento de la población) rondaban 56 por ciento de las muertes por el coronavirus (Wu et al., 2020).

Los ejemplos anteriores apoyan las principales teorías epidemiológicas, mismas que consideran que cuando mejoran las condiciones de vida disminuye la probabilidad de epidemias. La epidemiología sostiene de igual manera que el cambio en los ecosistemas, incluyendo el humano, explica el resurgimiento de viejas enfermedades infecciosas y el surgimiento de nuevas (Evans et al., 1994; McKeown, 1991). Cada cambio en la forma de producir, en la organización de la sociedad, en la utilización de los ecosistemas significa una modificación de la tela de la vida, de la cual los microbios son parte. Las sociedades precapitalistas conocieron variedades de enfermedades y epidemias y, a la par con los cambios en las formas de producción, se creaba un modo particular de producción de enfermedades.

${ }^{4}$ En los Estados Unidos los afroamericanos constituyen el 27.4 por ciento de los pobres, siendo el 12.7 por ciento de la población (Economic Policy Institute, 2018). 
La revolución neolítica, por ejemplo, basada en el excedente regular y almacenable en cereales o en ganado vivo domesticado, provocó el desarrollo de varias enfermedades de origen zoonótico por causa de la convivencia con animales.

Estas críticas al capitalismo en general y a sectores en particular se han planteado desde los 1970. En las últimas tres décadas conceptos como el principio de precaución, el análisis del ciclo de vida de los procesos productivos y la economía circular guían la atención a lo que tradicionalmente no se consideraba un problema de salud, como son los efectos de esos procesos o sectores productivos en el ecosistema como un todo.

Hay un sector que, sin embargo, ha quedado inmune al cuestionamiento. Se trata del sector biomédico. Podría tomarse como una paradoja, porque mientras se cuestiona el papel de diversos sectores económicos capitalistas se deja de lado uno que también lo es, y hasta se apuesta en él como solución. En este artículo incursionamos en el aludido aspecto, el cual ha sido poco analizado con relación a la pandemia y al capitalismo. Cabe mencionar, que debido a su amplitud, tomaremos un elemento central: los dos medicamentos con los que la moderna medicina capitalista ha logrado su hegemonía a escala mundial y ha marginando otras alternativas terapéuticas.

\section{La medicina en épocas precapitalistas}

La medicina es una rama de la división social del trabajo con particularidades propias. Tiene como objeto de trabajo el cuerpo humano, al igual que ocurre con la cosmética, los deportes, ciertas artes y, en menor medida, la 
industria de la alimentación. Esto es una diferencia frente a la mayoría de las otras ramas que tratan con la naturaleza externa al cuerpo humano. El organismo humano como objeto de trabajo de la medicina no está aislado del contexto en que vive, de manera que la medicina debe contemplar las interrelaciones del organismo con el ambiente, lo que puede generar desequilibrios al interior del primero. Ambos elementos, el externo y el interno, pueden alterar el equilibrio de salud de las personas. Al surgir la epidemiología demuestra que cuando existen enfermedades extendidas en una población sus causas son ajenas al comportamiento individual de la persona, son colectivas, y deben ser enfocadas con políticas económicas, sociales y de salud pública (Evans et al., 1994).

La medicina y sus terapias es tan antigua como el Homo sapiens y, posiblemente anterior. Es sabido que vegetales con propósitos medicinales son usadas por una amplia gama de animales. Chimpancés y gorilas registran varias decenas de usos medicinales de plantas y puede intuirse que todos los antepasados del Homo sapiens los utilizaban (Hardy, 2018). Hay indicaciones que el Homo neandertal usaba plantas medicinales (Lietava, 1992).

Se conocen registros escritos de remedios y prácticas medicinales en el antiguo Egipto desde el 1800 a.C., como el Kahun Gynaecological Papyrus, y, al menos, siete papiros más (Jouanna y Eijk, 2012). La medicina egipcia se trasmite a la griega, árabe, romana, india y, tal vez, a la china (Lewis, 2016; Subbarayappa, 2001). Esta tradición llegó a Europa desde el mundo árabe, y fue sistematizada por el alquimista Paracelso sobre finales del siglo XV.

Si se hace abstracción de las muy diversas diferencias entre las terapias precapitalistas, todas tienen puntos en común. Para nuestros fines nos interesa resaltar tres. Una se vincula con el enfoque holista y vitalista de las 
terapias precapitalistas. El propósito de la terapia precapitalista es restaurar la fuerza vital del paciente (De Klerk, 1979). Este enfoque está incorporado a la tradición milenaria en medicina (antigua medicina egipcia, árabe, china, india, espagírica, alquimia, etcétera) (Federspil y Sicolob, 1994).

Es probable que el escaso desarrollo de las fuerzas productivas de las sociedades precapitalistas creara ideologías y religiones proclives a adaptarse a la naturaleza, antes que enfrentarse a ella. En el nivel de un organismo individual aquel espíritu de adaptación se manifiesta como la búsqueda de la armonía interna y con el entorno. De hecho, no es hasta la revolución industrial que la idea de una naturaleza posible de ser alterada a voluntad penetra todos los poros de la sociedad capitalista (Passmore, 1978).

Recuperar la fuerza vital de un organismo enfermo requiere conocer las características, historia clínica, estilo de vida, y otras particularidades por parte del terapeuta, además del agente externo dado el caso. Tales requisitos explican el segundo punto en común de las terapias precapitalistas: su carácter elitista.

En un afán de considerar este segundo punto en común de las terapias precapitalistas, el elitismo, es necesario dejar de lado en el análisis el extenso conocimiento médico de las poblaciones, basado en la tradición personal y en medicamentos que pueden ser obtenidos en las inmediaciones de la vivienda del paciente. El carácter rural de estas sociedades permite ese conocimiento y prácticas terapéuticas asociadas.

La medicina más especializada, no obstante se encuentra en manos de médicos profesionales que atienden a una élite. Esto es obligado por las características del tratamiento holista, que supone un seguimiento desde la cabecera del paciente durante mucho tiempo. Las decenas o centenas de medicamentos provienen de muy lejanas regiones y variados ecosistemas, 
y su preparación exige realizarla en el momento. Muchas de esas preparaciones utilizan fermentaciones especiales, acciones de la luna u otros astros en momentos astronómicos particulares, lo que puede requerir semanas de preparación, según lo señalado por procesos espagíricos heredados de la antigüedad. La medicina precapitalista de vanguardia era medicina para una élite.

El tercer elemento en común de las terapias precapitalistas es el reconocimiento de la posibilidad de emplear tanto la ley de semejanza como la ley de contrarios en el proceso terapéutico. Se trata de dos vertientes mágico-filosóficas de origen paleolítico: la magia por similitud y la magia por oposición (Frazer, 2005). El medicamento puede curar porque en personas sanas provoca síntomas semejantes o porque elimina los síntomas de la enfermedad. Dos principios filosófico-ideológicos llevados a la práctica médica y derivados de la experimentación.

\section{Las relaciones sociales de producción conducen al surgimiento de la medicina capitalista}

El entramado de diferentes terapias de origen precapitalista cambia radicalmente con la revolución industrial y el capitalismo.

La revolución industrial de finales del siglo XVIII en Inglaterra y las políticas asociadas concentran a la población en grandes ciudades. La urbanización separa a los trabajadores y sus familias de cualquier contacto y conocimiento de la materia prima local con propiedades medicinales. Los ciudadanos pierden el conocimiento terapéutico tradicional más elemental, que pasa a concentrarse exclusivamente en el sector médico. 


\section{GUILLERMO FOLADORI}

Al mismo tiempo, la población hacinada, con escaso saneamiento y elevada pobreza, se convierte en caldo de cultivo para enfermedades contagiosas. El capitalismo crea un nuevo modo de producción y, con ello, un nuevo modo de producción de enfermedades.

La fuerza de trabajo enferma genera cortes y retrasos en los procesos industriales y, más importante aún, en la ganancia de los empresarios. Los Estados se ven forzados a un cambio radical en el tratamiento de las enfermedades, y la Ciencia y Tecnología (C\&T) a dar una respuesta terapéutica masiva, ya no elitista.

Se generaliza la atención médica a las clases trabajadoras para mantener el ritmo de la producción industrial. Así, la medicina deja de ser una ciencia hermética y elitista, como lo era en épocas precapitalistas. Se crean escuelas de medicina y se normaliza su quehacer en profesiones reglamentadas y en instituciones (hospitales, laboratorios); se establecen códigos y, lentamente, también regulaciones para fiscalizar la profesión y los medicamentos. ${ }^{5}$ Con el advenimiento del capitalismo aparece la necesidad de la atención masiva y, con ello, la democratización de la atención médica.

La medicina cambia con respecto a la herencia precapitalista. Cambia en la filosofía, en el objeto de atención, en la metodología de tratamiento, en el tipo de medicamento. Cambia radicalmente en todos sus aspectos. No es un cambio repentino, sino pausado y que llevó al menos un siglo y medio de convivencia con terapias precapitalistas hasta alcanzar su hegemonía. Con todo y eso, no eliminó las terapias precapitalistas, pero sí las marginó en la educación, en la aceptación pública y en el mercado.

${ }^{5}$ Sólo después de la Segunda Guerra Mundial se establecen en algunos países prácticas de fiscalización de medicamentos (Boxtel et al., 2008:65). 
Filosóficamente, el capitalismo surge imbuido del mecanicismo heredado de la revolución mecánica del Renacimiento, y catapultado por la revolución industrial. El mecanicismo filosófico asociado a Descartes (1596-1650) alcanza la medicina con el símil del cuerpo humano con una máquina, donde las partes bien integradas llevan al buen funcionamiento del organismo. Mientras la filosofía precapitalista tiene una visión holista de un organismo y supone que de esa totalidad emana una fuerza vital, la filosofía mecanicista entiende que el organismo se integra por órganos y células que funcionan de manera relativamente independiente.

El avance de la química inorgánica entrado el siglo XIX es clave para erosionar el vitalismo, al mostrar que se pueden sintetizar compuestos orgánicos a partir de inorgánicos, lo cual hace pensar que no se requieren más que fuerzas físico-químicas para explicar las enfermedades (De Klerk, 1979). ${ }^{6}$

La visión mecanicista es eficiente y más simple que las vitalistas para enfrentar al organismo enfermo sin necesidad de sofisticados diagnósticos y prognosis de la enfermedad. El mecanicismo reduccionista supone que si «haces X obtienes Y», ello en términos médicos significa que «X remedio cura Y enfermedad». El vitalismo precapitalista supone que «X está contenido en $Y »$, lo cual en términos médicos significa que «para curar $Y$ no basta con conocer X, aunque es necesario». Dicho de otra manera, la concepción mecanicista supone que la suma de las partes hace el todo, mientras que la perspectiva vitalista entiende que puede haber resultados emergentes, fuerzas contrarrestantes y situaciones particulares de un organismo, que modifican la trayectoria del desarrollo de la enfermedad, y,

${ }^{6}$ En 1828, Friedrich Wöhler sintetizó un compuesto orgánico, la urea, a partir de inorgánicos. 


\section{GUILLERMO FOLADORI}

por tanto, el remedio necesario. Causas pasadas, o la historia previa de la persona, pueden ser más importantes que la predicción de evolución de la enfermedad en sí misma. ${ }^{7}$

La visión mecanicista permanece hoy día en la medicina molecular o biomedicina, ${ }^{8}$ y es parte de la teoría neodarwinista que da prioridad al gen. Las propiedades de un organismo complejo se explican por sus partes más elementales y sus interacciones físico-químicas, hasta el reduccionismo genético que explica las propiedades biológicas de un organismo por sus genes (Tauber y Sarkar, 1993). A partir del siglo XXI ese principio mecanicista comienza a ser cuestionado por la moderna biología sistémica, sin que por ello se haya abandonado ni cuestionado en el quehacer médico. ${ }^{9}$

${ }^{7}$ Para una distinción filosófica y metodológica entre vitalismo y mecanisismo véase Hoernlé (1918), y Fiedelpiel y Sicolob (1994). Estos últimos autores explican que en la actualidad las posiciones mecanicistas y vitalistas permanecen, aunque unas se han desprendido de las perspectivas más radicales del determinismo y las otras de una fuerza vital externa al cuerpo y que guiaría su finalidad.

${ }^{8} \mathrm{Al}$ decir de Marcum «the chief absolute presupposition of the biomedical model is reductionism, which is intimately associated with an ontological commitment to physicalism or materialism (...) Whereas theoretical reductionism simplifies theories and ontological reductionism simplifies the phenomena, methodological reductionism simplifies research through dissecting higher order phenomena into their constitutive components at the lower order» (Marcum, 2008:24-25).

${ }^{9}$ El conocimiento de la estructura del ADN, aislándola en una célula, condujo a la conexión mecánica entre un gen, una proteína y una función durante las últimas décadas del siglo XX. Aunque ese razonamiento sólo explicó el 1.5 por ciento de los genes humanos, el resto fue considerado «basura». Es en el siglo XXI que surge la llamada biología sistémica, que reconoce la posibilidad de que información de la totalidad oriente la particularidad (top-down) (Fang y Casadevall, 2011; Levi-Montalcini y Calissano, 2006). No obstante, sumar la metodología reduccionista que sigue dando importantes resultados prácticos, con la sistémica no es más que un nuevo reduccionismo, ahora a mayor escala, distante aún del holismo de las grandes tradiciones médicas vitalistas, pero un avance en el encuentro del enfoque holista con el reduccionista (Mazzocchi, 2011). «Reductionism is at the philosophical heart of the molecular biology revolution. Holistic science, the opposite of reductionistic science, has also acquired a bad name, perhaps due to an unfortunate association of the word holistic with new age 
Desde principios del siglo XIX hasta la actualidad la medicina capitalista fue escalando niveles de reduccionismo (Marcum, 2008; Tauber y Sarkar, 1993). De la enfermedad al organismo infectado, del organismo a la célula, de la célula a las moléculas, de las moléculas a las proteínas, de las proteínas a las micro y nanopartículas. El reduccionismo ha dado importantes avances a la medicina. Muchos antibióticos fueron resultado de extrapolar lo simple a lo complejo. El organismo fue entendido como una suma de moléculas, a las cuales podía ser reducido y explicado.

La identificación cotidiana que acompaña tal evolución son los nombres aplicados vulgarmente: de medicina alopática — es decir antivitalista, antiholista_- a medicina celular, a biomedicina, a medicina genética y otras más recientes. Dos siglos transcurren de exitoso pero relativo triunfo, que desplaza, no sin momentos de retroceso y crisis a las terapias de impronta precapitalistas (vitalistas) que todavía prevalecen, como las diversas modalidades de las medicinas complementarias y alternativas (naturistas, acupuntura, homeopatía, ayurveda, etcétera).

Vale advertir que el reduccionismo no es sólo un resultado científico. Es el resultado más amplio de una trayectoria productiva basada en el costo-beneficio que únicamente puede impulsar una C\&T que se ajuste a él, o sea que rinda resultados inmediatos con un rápido retorno del capital invertido. Aunque eso suponga ignorar e inclusive derribar caminos alternativos potencialmente más sustentables.

Otra característica teórica y metodológica que las relaciones capitalistas imponen a la medicina y se asocia al reduccionismo, es inclinación

pseudoscience. However, fortunately there is an increasingly popular euphemism that lacks the pejorative connotations of holism for scientists—-systems biology» (Fang y Casadevall, 2011:1401). 
alopática. De la tradición precapitalista que aplica en sus terapias la ley de semejanza o la ley de contrarios según el caso, la medicina capitalista se inclina casi exclusivamente por la ley de contrarios, que trata las enfermedades suprimiendo los síntomas o procesos fisiopatológicos. Menospreciar la potencialidad de la ley de semejanza no es una opción científica, es la imposición de la experimentación química sujeta a la presión industrial por resultados. Los métodos terapéuticos capitalistas no pueden incorporar principios como el planteado por Paracelso, en el sentido de que además de las características del medicamento (sea animal, vegetal o mineral), la dosis o cantidad hace la diferencia. Esto hubiera obligado a probar infinitas cantidades de la misma materia prima en distintos tamaños de dosis, algo inviable por una ciencia médica sujeta al ritmo capitalista y a una tecnología mayoritariamente manual durante el siglo XIX. Para la medicina capitalista el reduccionismo metodológico es obligado.

La expresión práctica y material de la orientación capitalista de la medicina se apoya en la química para catapultarse. El aislamiento de una bacteria, su identificación como elemento patógeno, la posibilidad del cultivo celular y el desarrollo de un elemento que la controle o mate es uno de los logros que impacta de manera más decisiva el desarrollo de la medicina capitalista. Aparece la teoría del germen de Pasteur.

La teoría del germen cambia radicalmente la metodología de tratamiento de la enfermedad, la cual no es más que un desajuste en el equilibrio del organismo, en la energía vital debilitada, como en la tradición médica milenaria. Es el resultado de un elemento externo, un patógeno, que se introduce en el organismo.

Desaparece el organismo enfermo como objeto de tratamiento médico y, en su lugar, se manifiesta la enfermedad. La enfermedad, no el enfermo, 
pasa a ser el objeto de tratamiento con el medicamento para combatir al patógeno. El propósito ya no es reestablecer un supuesto equilibrio vital. El propósito es identificar el germen, el patógeno, y matarlo, reducirlo o evitarlo. La medicina capitalista abandona los conceptos de equilibrio del organismo, de fuerza vital, de análisis holista, por el lenguaje militar: combatir al enemigo, matar al patógeno. Los antibióticos son el «caballito de batalla» indiscutible con el cual la medicina capitalista conquista su hegemonía luego de más de un siglo de investigación y desarrollo (I\&D) y su culminación con aplicaciones masivas durante la Segunda Guerra Mundial, aunque en competencia con medicamentos provenientes de otras terapias.

La inclinación alopática - ley de contrarios — se fortalece con los antibióticos. Para cada enfermedad una «bala de plata». Los antibióticos son el mejor ejemplo de la aplicación de la ley de los contrarios y de resultados inmediatos. La elaboración de un medicamento para una enfermedad, y con relativa independencia de las características del paciente, permite saltar la barrera del tratamiento individualizado y la subordinación del terapeuta al seguimiento de la enfermedad en cada paciente. Los medicamentos pasan a estar al alcance del paciente, reducen la necesidad del médico. Se establece la necesidad de producción industrial de medicamentos y el mercado como medio de acceso. El médico se transforma en un intermediario entre la industria farmacéutica y el paciente. ${ }^{10}$

Paralelo a la generalización de medicamentos para tratar la enfermedad ocurre un distanciamiento del médico respecto del conocimiento de

\footnotetext{
${ }^{10}$ «When consumers go to see their physician, their requests for specific medications they have seen advertised are likely to be honored. Doctors do not want to lose patients, and they need to move quickly. Given expectations to see greater numbers of patients, it may be easier and faster to write a prescription than to discuss alternatives» (Sekerka y Benishek, 2018:121).
} 
las propiedades curativas del medicamento. Al conectar mecánicamente el medicamento con la enfermedad, la medicina capitalista exonera las particularidades del paciente, o las reduce a la lista de observaciones de resultados adversos que aparecen en el prospecto del medicamento y es lo que el médico requiere saber.

La medicina capitalista se impone de forma hegemónica sobre las terapias precapitalistas aupada por la aplicación de sus medicamentos durante la primera, pero más significativamente la Segunda Guerra Mundial cuando se generaliza la producción de antibióticos. De la Segunda Guerra Mundial surge la industria farmacéutica de escala, que se impone sobre todo tipo de industria estatal y de pequeñas empresas de medicamentos en Estados Unidos y otros países centrales (Microbiology Society, n.d.).

Esta hegemonía de la medicina capitalista no es resultado, claro está, de los cambios filosófico-metodológicos, ni de la producción de antibióticos, aunque estos últimos hayan sido clave, de modo simultáneo hubo avances importantísimos en cirugía, implantes, rayos X, antisépticos. Las dos guerras mundiales son el ámbito donde la medicina capitalista se bautiza como hegemónica.

Hay un segundo «caballito de batalla» de la medicina capitalista de enorme relevancia para lograr su hegemonía: las vacunas. El medicamento que mata al patógeno y del cual el antibiótico es la mejor expresión, es útil para combatir la enfermedad, pero no para impedirla. Las enfermedades infecciosas y las epidemias requieren un tratamiento diferente.

La medicina capitalista hereda una tradición centenaria basada en el tratamiento de algunas enfermedades infecciosas. Si dejamos de lado las políticas de aislamiento y confinamiento de los infectados, que fue utilizada posiblemente desde hace miles de años, la inoculación fue el medicamento. 
La inoculación y su heredera la vacunación presentan una contradicción aparentemente antagónica en un contexto capitalista. Primero, porque filosófica y metodológicamente aplica el principio opuesto a la ley de contrarios. La inoculación y posterior vacunación se basa en la ley de similitud. Se inyecta el virus o atenuaciones de él para evitar la enfermedad que de otra forma provocaría. Es el principio de lo igual cura lo igual, con su tradición milenaria de magia simpática:;1 ${ }^{11}$ sin embargo, el antagonismo más importante con las relaciones capitalistas no es de orden filosófico y metodológico, es de orden puramente mercantil.

La vacunación es una terapia preventiva, tendiente a inmunizar a la población para evitar la enfermedad. El objetivo no es curar una enfermedad como con el antibiótico. El objetivo es evitar la enfermedad, pero en un sinsentido mercantil. Con inmunidad no hay enfermedad, sin enfermedad no hay mercado, y sin mercado no hay producción de vacunas. He ahí la contradicción entre medicamentos preventivos en un contexto capitalistas. Esta contradicción es resuelta mediante el apoyo de sectores diferentes al propiamente médico: la política acude a superar la contradicción, como veremos más adelante.

Aunque la inoculación haya sido una práctica milenaria, el laboratorio capitalista consigue individualizar al virus, manipularlo, atenuarlo o «recortarlo». Transforma el tradicional proceso de inoculación en vacunación, más seguro y efectivo que su antepasado.

"I Podría argumentarse que al aplicar la ley de simpatía la medicina capitalista muestra de manera indirecta, que el principio opuesto cristalizado en los antibióticos no era el único camino; en todo caso resultó de la imposición de las relaciones capitalistas demandando resultados económicos inmediatos y por su lucha ideológica contra las corrientes precapitalistas. 


\section{GUILLERMO FOLADORI}

La vacunación se extiende rápidamente desde principios del siglo XX, aupada por las demandas de las sucesivas guerras. Debe recordarse que el contagio premeditado fue utilizado en situaciones de guerra desde tiempos lejanos, con la contaminación del agua del enemigo, el envío de enfermos a los campamentos enemigos, o artículos que pudiesen contagiar. En la tradición militar la enfermedad siempre fue un arma de guerra y también de defensa. La institución militar requiere inmunizar a sus combatientes con igual importancia que entrenarlos militarmente. Medicina y guerra constituyen una misma trayectoria científica.

Antibióticos y vacunas son los dos «caballitos de batalla» principales de la medicina capitalista a lo largo del siglo XIX y XX, si hacemos abstracción de la gran cantidad de innovaciones en materia técnica e instrumental y de diagnóstico.

\section{Las crisis de la medicina capitalista y su soporte externo}

Ningún desarrollo científico-tecnológico es lineal. Todos sufren de oposición y crisis. La medicina capitalista no es la excepción. Estas crisis provienen tanto de elementos externos como internos del propio desarrollo. En lo que sigue mencionamos dos crisis que corresponden a los antibióticos y a las vacunas, respectivamente. Tales crisis han sido superadas, en gran medida, por el apoyo externo, en particular por el aparato jurídico, aunque también por mecanismos administrativos y académicos para soporten la medicina capitalista.

Luego de algunas décadas de éxito en la aplicación de vacunas y un par en el caso de los antibióticos, el cirujano general de Estados Unidos 
dice en un informe al Congreso en la segunda mitad de la década de 1960: «It's time to close the book on infectious diseases, declare the war against pestilence won, and shift national resources to such chronic problems as cancer and heart disease» (citado por Spellberg, 2008).

La alegría dura poco. Entre 1980 y 1992 las muertes por enfermedades infecciosas en Estados Unidos se incrementan 58 por ciento (Hughes, 1998). Además del resurgimiento de viejas enfermedades, nuevas enfermedades infecciosas emergen y los analistas lo explican por las mismas razones que hoy día se atribuyen a la COVID-19, como cambios en los ecosistemas y uso del suelo, incremento de viajes y comercio internacional, cambio climático, relajamiento de medidas sanitarias por las políticas neoliberales e incremento de las migraciones (Kimball, 2000; Morse, 1995; World Health Organization, 1999).

Las críticas más radicales se orientan a reivindicar la importancia de la salud y medicina pública sobre la privada, pero continúan apostando a la trayectoria de medicina capitalista basada en antibióticos, vacunas, antivirales y otros medicamentos, sin cuestionar las bases epistemológicas ni las políticas de lock-in para evitar la competencia de otras terapias.

La crisis de los antibióticos, después del gran éxito durante la Segunda Guerra Mundial con la penicilina y un par de décadas posteriores, se manifiesta en el resurgimiento de nuevas enfermedades infecciosas, con la rápida adaptación de los microbios a las drogas. Para la big pharma el desafío es doble. Por un lado, el tiempo y costo de las nuevas drogas. El costo de I\&D podía llegar a más de 500 millones de dólares a finales del siglo XX (Kettler, 1999); suma que debía ser recuperada durante la vida útil de la patente (20 años). Según algunos analistas, durante los primeros 12 años la empresa recupera sus costos; los últimos ocho son de ganancia. 
Sin embargo, el siguiente desafío reduce las posibilidades de éxito. Los microbios se adaptan más rápido a las drogas que lo que necesita el capital para recuperarse, por tanto no hay negocio (Grabowski y Vernon, 1994; World Health Organization, 2020).12 El sobreuso de antibióticos incrementa el ritmo de la selección microbiana, la mutación y resistencia. Un círculo vicioso se forma: la big pharma impulsa la venta de antibióticos, el incremento del consumo acelera la resistencia de los microbios y ésta hace inútiles los antibióticos. El 7 de marzo de 1994 la revista Newsweek publica un artículo titulado «The end of antibiotics?» (Begley et al., 1994); y la portada del número 12 de septiembre de 1994 de la revista Times rotulaba «Revenge of the killer microbes».

Mientras los microbios se adaptan a las balas de plata de los antibióticos, investigaciones indican que 75 por ciento de los antibióticos tienen un efecto terapéutico cuestionable. Como respuesta, la big pharma reacciona produciendo antibióticos más fuertes y de espectro más amplio — cephalosporins y fluoroquinolones-, con lo cual crean supermicrobios cada vez más resistentes (Wise et al., 1998).

Sin negar la eficiencia histórica de corto y mediano plazo de los antibióticos, en el largo plazo esa trayectoria tecnológica crea supermicrobios resistentes, efectos colaterales en los organismos y reducción de la inmunidad en aquellos que los toman regularmente. El paradigma hegemónico es cuestionado. El vicepresidente de genética de la multinacional GlaxoSmithKline declara, en 2003, que los fármacos más caros no ofrecen

12 «Declining private investment and lack of innovation in the development of new antibiotics are undermining efforts to combat drug-resistant infections, says the World Health Organization ... research and development for antibiotics is primarily driven by small- or medium-sized enterprises with large pharmaceutical companies continuing to exit the field» (World Health Organization, 2020). 
ningún beneficio a cerca de la mitad de los pacientes, y que la mayoría de los medicamentos — más de 90 por ciento- sólo sirven a entre 30 y 50 por ciento de los enfermos (Alliance for Human Research Protection, 2010). Poco a poco la big pharma abandona la I\&D en nuevos antibióticos. La crisis de los antibióticos es una crisis interna a su propio desarrollo como medicamento terapéutico.

El caso de las vacunas es diferente. Las vacunas se generalizan durante las grandes guerras. Desde finales del siglo XIX los soldados fueron sujetos de prueba de vacunas y décadas más tarde de antibióticos. En época de guerra la obligatoriedad de la vacunación y uso de medicamentos en los soldados evade cualquier protocolo médico, bajo el paraguas del estado de emergencia (Sekerka y Benishek, 2018). Esto existe aún hoy y es aplicado para la COVID-19. La vacunación obligatoria representa un mercado cautivo y asegurado.

Después de la Segunda Guerra Mundial el mercado para las vacunas corre el riesgo de reducirse significativamente. Para evitarlo, la big pharma presiona a los gobiernos para hacer obligatorias algunas vacunas en infantes, con ello se matan dos pájaros de un tiro. Por un lado, se inmuniza a la población, cumpliendo así con el cometido último de la industria de vacunas de evitar los contagios y epidemias. Por otro lado, se cumple con el cometido primario de la big pharma, de garantizar el mercado y las ganancias.

Desde los 1970 se producen vacunas con múltiples fines. La «triple» (sarampión, paperas y rubeola), por ejemplo, se introduce en Estados Unidos y luego en Reino Unido; pero a finales del siglo XX surgen reclamos de afectados, muchos aluden que desencadena autismo en los niños, y artículos científicos a favor y en contra de la vacunación se hacen cada vez más 
comunes (Coulter, 1993). Más recientemente, a principios del siglo XXI, se publican varias investigaciones científicas que afirman los efectos adversos de las vacunas que utilizan aluminio como adyuvante para canalizar el producto activo (Gherardi et al., 2001; Gourier Frery et al., 2019).

Así, dos hechos se retroalimentan para crear una crisis de las vacunas. Uno son los casos de efectos adversos. Otro es la oposición de sectores de la población, en particular madres y padres de niños que deben vacunarse obligatoriamente. Las organizaciones contrarias a la vacunación existen desde las formas pretéritas de inoculación, pero durante los 1980 y los 1990 crecen en los países desarrollados.

Las organizaciones antivacuna acuden a juicios contra la big pharma en casos de efectos adversos registrados. En Estados Unidos se institucionaliza un programa para encauzar estos reclamos. Dos décadas después más de 16 mil 500 casos son llevados a las cortes, con un tercio de los casos resueltos favorablemente para los afectados y 3.7 mil millones de dólares pagados por indemnización (Holland, 2017). La big pharma reacciona con mayor lobby sobre los gobiernos. Durante los 1990 la big pharma logra imponer en la OMS y gobiernos más vacunas obligatorias en niños. En países como Estados Unidos, Francia e Italia los niños en edad escolar reciben actualmente entre 10 y 15 vacunas obligatorias, y algunas de ellas en varias dosis (Curley, 2019; Forster, 2017). Paralelamente, crecen las ONG que demandan suprimir la obligatoriedad.

La crisis de antibióticos y vacunas repercute en la competencia con las medicinas complementarias y alternativas de origen precapitalista. Durante las últimas dos décadas del siglo XX el consumo de medicamentos y servicios de la medicina complementaria y alternativa crece sostenidamente en varios países desarrollados (Fisher y Ward, 1994), como 
resultado de la crisis de los antibióticos, del aumento de sus precios y de los efectos secundarios de las vacunas. En Estados Unidos, Eisenberg et al. (1998) comparan 16 terapias alternativas usadas por adultos en 1997 en relación con 1990. El concepto genérico de folk remedies se incrementa 2000 por ciento. Un artículo en Journal of the American Medical Association (JAMA) reporta que 40 por ciento de las familias de una muestra en Estados Unidos usa alguna forma de cuidado de salud alternativa durante el año previo (Astin, 1998). Estas medicinas complementarias y alternativas no son parte de la ciencia «normal», y, por lo tanto, no reciben recursos, ni tiempo y espacio que los consumidores demandan, y han estado sujetas a restricciones (Marwick, 1994). En otro número de JAMA, los lectores de la revista — supuestamente estudiantes y profesionales de la salud- Colocan las medicinas complementarias y alternativas en séptimo lugar de importancia para que artículos sobre el tema sean publicados, pero los expertos — posiblemente árbitros de la revista — consideran su importancia en los lugares 68 y 73 (Lundberg, 1998); lo que muestra la distancia entre los estudiantes más ávidos de novedades de los árbitros más cerca de la «ciencia normal». La represión ejercida por científicos «normales» sobre grupos de investigación en medicina complementaria y alternativa en algunas instituciones de salud, como en el caso de los National Institutes of Health, es denunciada (Marwick, 1994). Paralelamente, demandas de la ciencia «normal» contra la medicina alternativa se incrementan sostenidamente, luego de que el público acudiera más a estas medicinas después de los 1980 (Skolnick, 1994). Estrategias de barreras sociales y científicas han sido un mecanismo para mantener al paradigma «normal» libre de competencia.

La medicina capitalista reacciona a su crisis interna y a los embates de las terapias competitivas con propaganda, lobby, y diversas prácticas de 
lock-in. Según el sociólogo Kuhn (2012), la ciencia «normal» es aquella que desarrollan los científicos que comparten el paradigma hegemónico durante un periodo. El paradigma supone un consenso en ciertas soluciones o enfoques. Los científicos están entrenados dentro del paradigma y adoptan esos valores. La fidelidad al paradigma determina la vía mediante la cual el fenómeno a investigar es seleccionado, los instrumentos y métodos a usar y la literatura en la que se basa. Lejos de ser ciencia «neutral», el paradigma previene, mediante mecanismos de cierre (lock-in procedures), que se desarrollen paradigmas alternativos que no corresponden con la ciencia «normal».

A diferencia del caso de los antibióticos, donde los agentes de la propia medicina capitalista, incluyendo la OMS y las principales revistas médicas, advierten que esa trayectoria entra en crisis, en el caso de las vacunas, los agentes de la medicina capitalista realizan un verdadero lock-in del tema. En 1998, por ejemplo, y con relación a la vacunas «doble» y «triple», profesionales de la salud críticos son presionados a abandonar sus cargos y diversos pleitos jurídicos instituidos al respecto (Ho, 2001). Otros ejemplos del lock-in son reportados en los comentarios de la British Medical Journal respecto de la obligatoriedad de la vacunación en Reino Unido (Stone, 2017).

Junto a las barreras académicas y profesionales de las terapias alternativas, la big pharma desarrolla una profusa propaganda y lobby político, con el propósito de crear una cultura de la necesidad del consumo regular de los medicamentos por ella producidos y así mantener el organismo, al igual que la necesidad de alimento. Varios análisis coinciden en el papel de la big pharma con el establecimiento de una feroz política de propaganda, lock-in, corrupción política y otros mecanismos para mantener su 
hegemonía e inmunidad frente a las críticas. Muestran las concesiones político administrativas para descontar impuestos, las horas en los medios de comunicación, el efecto que crea un vínculo directo entre farmacia y consumidor, la orientación para crear la idea de enfermedades emergentes que respondan a una nueva medicina, el gasto en propaganda y lobby que compra a grupos opositores y a políticos, y el gasto en millones en juicios; de igual forma la compra de médicos y académicos que escriban buenas historias de sus medicamentos en revistas científicas, así como la colocación a sus empleados en las directivas de las universidades y de los colegios médicos (Angell, 2004; Fugh-Berman, 2010; Gøtzsche, 2013; Lundh et al., 2010; Rawlinson, 2017; Sekerka y Benishek, 2018).

En apariencia, la medicina capitalista está regulada por instituciones gubernamentales sin conflicto de interés con investigadores y productores de medicina; en la práctica, las mismas instituciones regulatorias y sus gobiernos establecen excepciones que terminan evadiendo los protocolos; tales excepciones son explícitas en momentos de guerra o de epidemia.

Una vez superadas las primeras etapas in vitro o en animales, la I\&D requiere de pruebas en humanos para probar los nuevos medicamentos. Para las pruebas y sus resultados estadísticos son necesarios numerosos pacientes y con diversas características (la edad y el sexo son las principales). La posibilidad de flexibilizar estos protocolos en momentos de epidemia o de guerra es una de las razones por las cuales la historia de los antibióticos y de las vacunas está íntimamente ligada a las guerras, donde los soldados son forzados a aplicaciones terapéuticas y se realizan experimentos con prisioneros.

Desde principios de los 1970, y durante 15 años, a los reclutas de Estados Unidos se les aplica una vacuna contra adenovirus, misma que luego 
fue descontinuada y vuelta a aplicar en la segunda década del siglo XXI. Durante la guerra del Golfo «Tormenta del Desierto» (1990-1991) la Marina de Estados Unidos vacuna a sus marinos con la pentavalent botulinum-toxoid, una vacuna no licenciada en el momento e inyectada sin el consentimiento de los pacientes, aunque acompañada de un folleto informativo, lo cual levanta discusiones legales y éticas por violar el Código de Núremberg (Annas, 1992; Appeal, 1992). Las excepciones para agilizar los procesos de desarrollo de medicamentos se convierten en práctica común y se incorporan a los criterios «normales».

Respecto de las vacunas y en Estados Unidos, los siguientes tres decretos son ilustrativos del sustento de la legislación a las vacunas de la big pharma. En los 1980 se aprueba el National Vaccine Injury Compensation Program, con sucesivas enmiendas hasta el presente. Se trata de una medida jurídica que incrementa el precio de las vacunas obligatorias para infantes, destinada a formar un fondo para compensar los juicios perdidos por la industria farmacéutica debido a resultados adversos de las vacunas. O sea, el paciente paga los resultados adversos de su medicamento.

En 2005 se aprueba la PREP Act, que invalida toda acción legal por efectos adversos contra compañías productoras e instituciones administrativas encargadas de vacunas en momentos de emergencia nacional (epidemias o guerras). Las investigaciones de vacunas contra el Ébola, Zika, gripe HINl entran dentro de la PREP Act y también las pruebas de las vacunas para la COVID-19.

En 2016 se aprueba el 21st Century Cures Act. Según la organización A Voice for Choice Advocacy, con ese decreto los pacientes que reciben tratamiento pueden ser utilizados para exámenes clínicos de drogas y dispositivos en la medida en que exista «mínimo riesgo», y para lo cual los 
pacientes no necesitan ser informados de estar dentro de una prueba que puede tener riesgo o efectos secundarios, contraviniendo el Código de Núremberg (A Voice for Choice Advocacy, 2018)..$^{13}$ Otros ítems del decreto también han sido ampliamente criticados (Furlow, 2017; Loe Fisher, 2015; Warren, 2016), como el cambiar los criterios estadísticos de las pruebas y hacerlas sin ensayos clínicos. Esto ya se venía haciendo, al menos desde principios del siglo XXI de una u otra forma (Osorio-de-Castro et al., 2015); todo ello con el propósito de hacer los exámenes de medicamentos y dispositivos más rápidos, cortos, baratos y totalmente computarizados..$^{14}$ El resultado es que en Estados Unidos la investigación y producción de vacunas es prácticamente inmune a cualquier tipo de juicio por efectos adversos (Bentley, 2017; Holland, 2017).

La trayectoria de la moderna medicina molecular hegemónica ha sido criticada ampliamente, inclusive desde dentro. Pero las críticas se han limitado a la mala administración, a la injerencia nefasta del mercado y abandono de I\&D en determinadas áreas, a la escasa eficiencia de algunos medicamentos como los antibióticos, a los efectos secundarios de muchos remedios, a la pérdida de inmunidad que el sobreconsumo de fármacos produce en los organismos, al excesivo patentamiento y a la corrupción de instituciones y prácticas fraudulentas de la big pharma. Los mismos críticos han mantenido, sin embargo, un radical lock-in de toda terapia alternativa y lo han hecho de forma aún más profunda respecto de las vacunas. El paradigma de la medicina hegemónica no se osa colocar en

${ }^{13}$ Valga anotar que la última fase de prueba de las vacunas antes de recibir la aprobación reglamentaria se debe realizar en humanos y es la más cara; de allí el ahorro económico para la big pharma de probarla gratis en el Ejército y en pacientes.

${ }^{14}$ Según Sekerka y Benishek, mil 400 lobbystas de la big pharma participaron en la discusión del decreto (2018:124). 


\section{GUILLERMO FOLADORI}

discusión, a pesar de evidencias y críticas. Se discuten las malas prácticas y resulta significativo que las críticas terminan siempre en la misma causa general: una falla del mercado, como si no fuese el buen funcionamiento del mercado lo que genera la inequidad y desigualdad de la producción, I\&D y prácticas médicas. ${ }^{15}$

\section{La pandemia de la covid-19 en contexto}

Dos meses después de publicitada la pandemia, noticias divulgadas por la Federación Internacional de la Industria Farmacéutica señalan que hay 30 antivirales en prueba, al menos cuatro corporaciones investigan en vacunas y hay otras varias iniciativas públicas en camino (El médico interactivo, 2020). De igual forma, países y corporaciones invierten fuertemente con el mismo propósito. Una conferencia virtual organizada por la Unión Europea en mayo del 2020, con el propósito de recabar fondos para fundar laboratorios destinados al desarrollo de vacunas y fármacos contra el SARS-CoV-2, recibe promesas de donación inmediatamente, tanto de países como de particulares (The New York Times, 2020).

La reacción de la medicina capitalista a la COVID-19 corresponde a las prácticas mencionadas anteriormente. Una vez más el virus es el enemigo que hay que debilitar, evitarlo o matarlo con fármacos o vacunas. ${ }^{16} \mathrm{La}$

${ }^{15}$ Un ejemplo del mal mercado es la siguiente frase en plena pandemia del Ébola: «It's a market failure because this is typically a disease of poor people in poor countries, and so there is no market), said Marie-Paule Kieny, assistant director-general of the World Health Organization, on Tuesday» (Millman, 13 de agosto de 2014).

${ }^{16}$ Valga recordar que los virus son clave en la evolución celular y están en la base de los componentes de la inmunidad necesaria para la adaptación (Broecker y Moelling, 2019; Villarreal, 
apuesta de la big pharma para contener la pandemia consiste en antivirales, otros fármacos y vacunas; los caballitos de batalla que resultaron equivocados en muchos casos. A diez meses de pandemia la única práctica que ha dado un resultado relativo ha sido el aislamiento social, una práctica que tiene miles de años de aplicación.

En mayo de 2020, en medio del aviso de potenciales vacunas en puerta y otros fármacos, revive la polémica sobre la inmunidad de los contagiados por el SARS-CoV-2 (Kirkcaldy et al., 2020). Se trata de una polémica que lleva más de un siglo, conocida como la teoría de la manada (herd immunity). Ésta sostiene que cuando una población alcanza un alto porcentaje de infectados o vacunados resultan inmunes. La teoría ha tenido gran cantidad de modificaciones y críticas desde que fue enunciada en el siglo XIX y también la han tenido los análisis empíricos no concluyentes para confirmarla (Fine, 1993), pero ha sido, y es usada, como argumento por la big pharma y la OMS para vacunar a toda la población. Es un gran negocio, ya que los porcentajes que requieren inmunización, según la teoría de la manada, deben ser mayores a 90 por ciento cuando se consideran poblaciones abiertas. Mas allá de lo inverosímil de vacunar a toda la población mundial, el negocio multimillonario igual funciona con escaso porcentaje de vacunados. Además, no está confirmado que un infectado no se reinfecte o sobre la duración temporal de la inmunidad, algo clave, ya que

2009). Todo indica que de no haber sido por un retrovirus, no existirían los mamíferos, de los cuales formamos parte los humanos; ya que fueron los virus los responsables por la modificación del ADN que permitió el desarrollo de las especies con placenta: «Although the evolution of pregnancy via the placenta might be some of the most persuasive evidence that viruses stashed deep within the genome can help give rise to new species, it's not the only proof. New studies revealing the role of endogenous retroviruses in the more recent evolution of humans show that these snippets of DNA are helping to blur the boundary between human and virus. Humans are, in a very real sense, part virus» (Arnold, 2016). 


\section{GUILLERMO FOLADORI}

cuanto menor la inmunidad, mayor el mercado. ${ }^{17}$ Lo reconocido es el hecho de no saber por qué, en algunos infectados la reacción de un organismo que genera anticuerpos necesarios para defenderse es mucho más rápida que en otros, y tampoco se tiene certeza sobre la correlación entre generación de anticuerpos y gravedad en la manifestación de la enfermedad (Kirkcaldy et al., 2020). Todo esto lleva nuevamente a la discusión teórica sobre el abandono, por parte de la medicina hegemónica, del concepto de enfermedad como desequilibrio del organismo como un todo, tal como lo tratan las medicinas complementarias y alternativas, refugiándose en una metodología reduccionista centrada en el virus. En este sentido es significativo que los antivirales y fármacos utilizados para los pacientes de la COVID-19 sean prácticamente los mismos, siendo que las agencias de salud señalan que la sintomatología puede ser bien diferente dependiendo de cada paciente (CDC, 2020; OMS, 2020).

El desarrollo de la C\&T de la medicina hegemónica ajusta su tecnología de vacunas a los requerimientos del mercado. La COVID-19 ha mostrado algunos cambios importantes en el propósito de algunas vacunas en investigación. Transforman, por ejemplo, el principio original de la vacuna que era preventivo y para una inmunidad de por vida, las vacunas para infectados necesarias de ser administradas repetidamente, como sucede con las vacunas contra la gripe y con algunas tecnologías de RNA modificado; o sea, una auténtica vacuna mercantil que sólo inmuniza si se repite periódicamente la dosis, garantizando la inmunidad y las ganancias simultáneamente.

${ }^{17}$ «Whether immunity occurs among individuals after they have recovered from COVID-19 is uncertain. Many human infections with other viral pathogens, such as influenza virus, do not produce a durable immune response» (Kirkcaldy et al., 2020:El). 
La aplicación de las medidas de emergencia se ha realizado en casi todos los países y, con ello, el relajamiento de los controles en los protocolos de I\&D. El antiviral remdesivir es aceptado por el ejecutivo de Estados Unidos en abril de 2020 para tratar la COVID-19 bajo el aval de la declaración de emergencia nacional de salud pública, pero sin la correspondiente aprobación de la FDA (Guimón, 2020), que ocurre en octubre. Y ello, a pesar de estudios - no conclusivos - de Wang et al. (2020), en el sentido de no haber pruebas estadísticas de sus ventajas (Wang et al., 2020) y declaraciones posteriores de la OMS en el mismo sentido. Las acciones de bolsa de la empresa productora del remdesivir aumenta inmediatamente con sólo el anuncio de la potencial aprobación (Guimón, 2020); los fármacos son primero un negocio, sólo si éstos pueden llegar a ser medicamentos. Otro ejemplo semejante es el del antiviral avigan, también para combatir la COVID-19 (Liu, 2020).

La recomendación oficial de uso o el uso obligatorio de un medicamento o vacuna es de gran utilidad para obtener pruebas estadísticas rápidas y sin mayores protocolos, pero, además, significa un enorme mercado para la big pharma, que vende al Ejército y los gobiernos como mercado cautivo y financista principal, tanto de la investigación como de las compras. Muchos países han comprado vacunas que están en I\&D, para garantizar el suministro cuando salgan al mercado, lo que de alguna forma presiona a financistas, investigadores, productores, intermediarios y compradores para que efectivamente lleguen al mercado, independientemente del riesgo de no pasar las pruebas protocolares.

Los momentos de epidemia y las medidas de emergencia representan grandes ingresos para la big pharma. No sólo porque las ventas están aseguradas, esos momentos también abaratan los costos de I\&D. Las pruebas 
son aplicadas gratis a reclutas. Hay ejemplos de algunas vacunas para la COVID-19 (AFP, 2020; Harkins, 2020; Martinez, 2020). Asimismo, hay total inmunidad para la big pharma en caso de efectos secundarios de los medicamentos; como ya se señaló, la COVID-19 se inscribe dentro de la Prep Act en Estados Unidos y comentadores apuntan: «The declaration is intended to foster the expeditious development of drugs and devices designed to prevent and treat COVID-19» (Lovells, 2020; U.S. Department of Health and Human Services, 2019).

No es casual la íntima relación entre medicina capitalista para la COVID-19 y el aparato militar en varios países. Algunas de las vacunas en investigación se realizan en laboratorios militares o asociados (AFP, 2020; Harkins, 2020). La Operation Warp Speed (OWS) es una iniciativa del gobierno de Estados Unidos para acelerar la producción de millones de vacunas contra la COVID-19. Significativamente, está dirigida por el antiguo presidente de la GlaxoSmithKliner junto a generales del Ejército (Kime, 2020). No hay que olvidar tampoco que la mayoría de la materia prima para la industria de vacunas proviene de laboratorios militares de alta seguridad que conservan, crían y modifican virus (Peters, 2018).

\section{Conclusiones}

El siglo XXI llega con guerras, migraciones internacionales masivas, crisis económicas y revoluciones tecnológicas (nanotecnologías, industria 4.0). Viene también con un incremento de epidemias. Información de la OMS muestra que la gravedad de la incidencia de pandemias se incrementa de manera constante luego de la primera década (e. g. SARS 2002-2003; gripe 
suína 2009-2010; MERS 2012; Ébola 2014-2016; COVID-19 2019). Desde cualquier ángulo el capitalismo está en crisis.

La pandemia de la COVID-19 es una de las manifestaciones de esa crisis más general del capitalismo como sistema social y económico y está estrechamente vinculada con la transformación de los ecosistemas. Las críticas a los diversos sectores económicos del capitalismo no se hacen esperar. Ocurre con la agricultura, ganadería, explotación forestal, industrias de comunicaciones, transporte, industria química, consecuencias derivadas del calentamiento global y muchas otras. En todos los casos las críticas a los sectores económicos se asocian a la modalidad capitalista de I\&D y de producción, lo cual no es solamente una cuestión técnica, sino que atañe a cómo la C\&T orientada por la ganancia provoca una trayectoria técnica con resultados adversos para la mayoría de la población, aunque sea de gran beneficio económico para algunos sectores involucrados.

Paradójicamente el sector médico permanece inmune a las críticas. Más aún, inmediatamente la big pharma se preocupa por publicitar que tiene la solución a la pandemia y lanza una fuerte campaña publicitaria sobre vacunas en I\&D y una batería de fármacos para tratar a los pacientes. A diez meses de la pandemia ni las vacunas llegan al mercado ni los medicamentos han sido exitosos para evitar las muertes derivadas de la COVID-19, mientras que el mundo alcanza más de 1 millón 300 mil muertos.

La pregunta, casi forzada, es si el camino de la C\&T de la medicina capitalista hegemónica no tiene contenido de clase como se reconoce en los otros sectores económicos causantes o facilitadores de la pandemia. Este artículo se enfoca precisamente en aquella paradoja. Se remonta a los principales elementos históricos que muestran el quiebre sustancial que sucede cuando las relaciones sociales capitalistas imponen un rumbo 
diferente a la tradición médica milenaria. Se resume el gran éxito práctico de la medicina capitalista, en particular en sus dos caballitos de batalla con que gana hegemonía a lo largo de los siglos XIX y XX, las vacunas y los antibióticos. No obstante, se destaca que tal hegemonía no la ganó por virtudes exclusivamente científicas y tecnológicas, sino porque fue apoyada por el aparato militar, jurídico, administrativo y académico-científico asociado. La moderna medicina capitalista creció y se consolidó gracias a las guerras y al imperio económico y la incidencia política de la big pharma. Sin negar el grado de eficiencia de sus medicamentos ha tenido traspiés que ha ocultado sistemáticamente en aras de mantener su hegemonía.

Infelizmente, en su vorágine gananciosa, la medicina capitalista ha echado a la basura los pañales junto con el bebé, desperdiciando una tradición de conocimiento médico de siglos basada en la visión holista del organismo enfermo, en favor de una reduccionista; aunque en la desesperación de la COVID-19 los sistemas de salud deben recurrir, a falta de recursos de la big pharma para contenerla, a las prácticas milenarias de aislamiento. En medicina, al igual que en los demás sectores de C\&T, el carácter de clase de sus trayectorias que privilegia los intereses del capital se muestra ineficaz para atender las necesidades sociales.

La crítica del artículo a la trayectoria biomédica capitalista no pretende cerrar los ojos a los éxitos de esa trayectoria en términos puntuales, sino mostrar su inclinación clasista. Adicionalmente, en un momento particular, como el de una pandemia, es imprescindible acudir a todos los recursos existentes; si la medicina capitalista es la que más avances y recursos dispone, no es posible ignorarla, a pesar de que esa misma medicina capitalista ignore a las terapias competidoras. La crítica de largo alcance a la trayectoria también es válida porque advierte sobre la posibilidad de que 
aun superando la pandemia y pese a los costos sociales asociados, esa medicina capitalista no se encamina a evitar próximas y sucesivas epidemias, ya que gracias a ellas sobreviven sus ganancias.

\section{Referencias}

A Voice for Choice Advocacy (2018). «21st century cures act HR34 (was HR6). AVFCA Objects». A Voice for Choice Advocacy. Recuperado de https:// avoiceforchoiceadvocacy. org/21st-century-cures-act/

Afelt, A., Frutos, R. y Devaux, C. (2018). «Bats, coronaviruses, and deforestation: toward the emergence of novel infectious diseases?» Frontiers in Microbiology, 9(702). https://doi.org/10.3389/fmicb.2018.00702

AFP (2020, 29 de junio). «Autoriza China vacuna contra el Covid-19 para su ejército». La Jornada. Recuperado de https://www.jornada.com.mx/Últimas/ mundo/2020/06/29/autoriza-china-vacuna-contra-el-covid-19-para-suejercito-6773.html

Alliance for Human Research Protection (2010, 26 de octubre). «Glaxo chief: ¿Our drugs do not work on most patients»». Alliance for Human Research Protection. Recuperado de https://ahrp.org/glaxo-chief-our-drugs-do-not -work-on-most-patients/

Angell, M. (2004). The truth about the drug companies: How they deceive us and what to do about it (lst ed). Random House.

Annas, G.J. (1992). «Changing the consent rules for desert storm». The New England Journal of Medicine, 326(11), 770-773. DOI: https://doi.org/10.1056/ NEJM 199203123261117 


\section{GUILLERMO FOLADORI}

Appeal, H. (1992). «Correspondance: medicine and ear». The New England Journal of Medicine, 327(15), 1096-1098.

Arnold, C. (2016, 28 de septiembre). The viruses that made us human. PBS, Nova. https://www.pbs.org/wgbh/nova/article/endogenous-retroviruses/

Astin, J.A. (1998). «Why patients use alternative medicine: results of a national study». The Journal of the American Medical Association, 279(19), 1548. DOI: https://doi.org/10.1001/jama.279.19.1548

Attkisson, S. (2019, 15 de septiembre). «5G technology could come with health risks, critics say». Komonews. Recuperado de https://komonews.com/news/ nation-world/5g-technology-promises-to-be-faster-could-it-come-withhealth-risks

Begley, S., Brant, M., Wingert, P. y Hager, M. (1994, 28 de marzo). «The end of antibiotics?». Newsweek, 47-51.

Boxtel, C.J.V., Santoso, B. y Edwards, I.R. (eds.) (2008). Drug benefits and risks: international textbook of clinical pharmacology. Ios Pr Inc.

Broecker, F. y Moelling, K. (2019). «Evolution of immune systems from viruses and transposable elements». Frontiers in Microbiology, 10. DOI: https://doi. org/10.3389/fmicb.2019.00051

Carrington, D. (2020, 17 de junio). «Pandemics result from destruction of nature, say UN and WHO». The Guardian. Recuperado de https://www. theguardian.com/world/2020/jun/17/pandemics-destruction-nature-unwho-legislation -trade-green-recovery

CDC (2020, 13 de mayo). «Coronavirus disease 2019 (COVID-19). Symptoms». Centers for Disease Control and Prevention. Recuperado de https://www.cdc. gov/coronavirus/2019-ncov/symptoms-testing/symptoms.html

Cheng, V.C.C., Lau, S.K.P., Woo, P.C.Y. y Yuen, K.Y. (2007). «Severe Acute Respiratory Syndrome Coronavirus as an agent of emerging and reemerging 
infection». Clinical Microbiology Reviews, 20(4), 660-694. DOI: https://doi. org/10.1128/CMR.00023-07

Coulter, H. (1993). Vaccination, social violence, and criminality: the medical assault on the American brain. North Atlantic Books.

Curley, B. (2019, 3 de agosto). «Should childhood vaccines become mandatory in the US?». Healthline. Recuperado de https://www.healthline.com/healthnews/should -childhood-vaccines-become-mandatory-in-the-us

De Klerk, G.J.M. (1979). «Mechanism and vitalism. A history of the controversy». Acta Biotheoretica, 28(1), 1-10. DOI: https://doi.org/10.1007/BF00054676

Eisenberg, D.M., Davis, R.B., Ettner, S.L., Appel, S., Wilkey, S., Van Rompay, M. y Kessler, R.C. (1998). "Trends in alternative medicine use in the United States, 1990-1997: results of a follow-up national survey». The Journal of the American Medical Association, 280(18), 1569-1575. DOI: https://doi. org/10.1001/jama.280.18.1569

El Médico Interactivo (2020, 16 de marzo). «Unos 30 medicamentos antivirales ya están siendo probados para conocer su eficacia contra el Covid-19». Recuperado de https://elmedicointeractivo.com/unos-30-medicamentos-antiviralesya-estan-siendo-probados-para-conocer-su-eficacia-contra-el-covid19/

EMFscientist (2017, agosto). «Llamamiento internacional: los científicos piden protecciónfrentea la exposición a loscampos electromagnéticos no ionizantes». Recuperado de https://www.emfscientist.org/index.php/emf-scientist-appeal

Evans, R.G., Barer, M.L. y Marmor, T.R. (eds.) (1994). Why are some people healthy and others not? The determinants of health of populations. A. de Gruyter.

Fang, F.C. y Casadevall, A. (2011). «Reductionistic and holistic science». Infection and Immunity, 79(4), 1401-1404. DOI: https://doi.org/10.1128/IAI.01343-10

Federspil, G. y Sicolob, N. (1994). «The nature of life in the history of medical and philosophic thinking». Am J Nephrol, 14, 337-343. 


\section{GUILLERMO FOLADORI}

Fine, P.E.M. (1993). «Herd immunity: history, theory, practice». Epidemiologic Reviews, 15(2), 265-302. DOI: https://doi.org/10.1093/oxfordjournals.epirev. a036121

Fisher, P. y Ward, A. (1994). «Medicine in Europe: complementary medicine in Europe».BMJ,309(6947),107-111.DOI:https://doi.org/10.1136/bmj.309.6947.107

Forster, K. (2017, 5 de julio). «France will make all vaccinations compulsory by law». The Independent. Recuperado de http://www.independent.co.uk/news/world/ europe/france-vaccination-mandatory-2018-next-year-children-healthmeasles-dying-anti-vaxxers-edouard-a7824246.html

Frazer, sir J.G. (2005). El folklore en el antiguo testamento (spanish edition): Frazer sir James George. Fondo de Cultura Económica.

Fugh-Berman, A.J. (2010). «The haunting of medical journals: how ghostwriting sold «HRT»». PLOS Medicine, 7(9), el000335. DOI: https://doi.org/10.1371/journal.pmed.1000335

Furlow, B. (2017). «US 21st century cures act secures health-care research funding». The Lancet Oncology, 18(1), 24. DOI: https://doi.org/10.1016/S1470 $-2045(16) 30636-2$

Gherardi, R.K., Coquet, M., Cherin, P., Belec, L., Moretto, P., Dreyfus, P.A., Pellissier, J.F., Chariot, P. y Authier, F.J. (2001). «Macrophagic myofasciitis lesions assess long-term persistence of vaccine-derived aluminium hydroxide in muscle». Brain, 124(9), 1821-1831. DOI: https://doi.org/10.1093/brain/124.9.1821

Gøtzsche, P.C. (2013). Deadly medicines and organised crime. How big pharma has corrupted healthcare. Radcliffe Publishing Ltd.

Gourier Frery, C., Frery, N., Berrebi, A., Cordier, S., Garnier, R., Isnard, H., Ravault, C. y Renaudeau, C. (2019). Aluminium. Quels risques pour la santé? Synthèse des études épidémiologiques. Volet épidémiologique de l'expertise collective InVS-Afssa-Afssaps. Santé Publique France. Recuperado de 
https://www.santepubliquefrance.fr/docs/aluminium.-quels-risques-pourla-sante-synthese-des-etudes-epidemiologiques.-volet-epidemiologiquede-1-expertise-collective-invs-afssa-afssaps

Grabowski, H.G. y Vernon, J.M. (1994). «Returns to R\&D on new drug introductions in the 1980s». Journal of Health Economics, 13(4), 383-406. DOI: https:// doi.org/10.1016/0167-6296(94)90010-8

Grubaugh, N.D., Ladner, J.T., Lemey, P., Pybus, O.G., Rambaut, A., Holmes, E.C. y Andersen, K.G. (2019). «Tracking virus outbreaks in the twenty-first century». Nature Microbiology, 4(1), 10-19. DOI: https://doi.org/10.1038/s41564 -018-0296-2

Guimón, P. (2020, 1 de mayo). «EUA aprovam o uso do remédio remdesivir para pacientes com coronavírus». El País. Recuperado de https://brasil.elpais. com/ciencia/2020-05-01/eua-aprovam-o-uso-do-remedio-remdesivirpara-pacientes-com-coronavirus.html

Hardy, K. (2018). «Plant use in the lower and middle palaeolithic: food, medicine and raw materials». Quaternary Science Reviews, 191, 393-405. DOI: https:// doi.org/10.1016/j.quascirev.2018.04.028

Harkins, G. (2020, 15 de junio). «More than 1,000 marine recruits volunteer for COVID-19 study at Parris Island». Military. Recuperado de https://www. military.com/daily-news/2020/06/15/more-1000-marine-recruits-volunteer -covid-19-study-parris-island.html

Heindel, J. y Birbaum, L.S. (2020, 23 de abril). «Endocrine-disrupting chemicals weaken us in our COVID-19 battle». EHN. Recuperado de https://www.ehn. org/chemical-exposure-coronavirus-2645785581.html

Ho, M.W. (2001, 12 de diciembre). «Another independent scientist falls victim over findings against MMR vaccine». The Institute of Science in Society. Recuperado de http://www.i-sis.org.uk/MMRautism.php 


\section{GUILLERMO FOLADORI}

Hoernlé, R.F.A. (1918). «Mechanism and vitalism». The Philosophical Review, 27(6), 628. DOI: https://doi.org/10.2307/2178444

Hogan, L. (2020, 23 de marzo). Navigating limits on product liability under the PREP Act for COVID-19 clinical trial activities. Hogan Lovells Publications. Recuperado de http://www.hoganlovells.com/en/publications/navigating-limits-onproduct-liability-under-the-prep-act-for-covid-19-clinical-trial-activities

Holland, M.S. (2017). «Liability for vaccine injury: the United States, the European Union and the developing world». Emory Law Journal, 67, 415-462.

Hughes, J. (1998). «Addressing emerging infectious disease threats. Accomplishments and future plans». Emerging Infectious Diseases, 4(3), 360-361. DOI: https://doi.org/10.3201/eid0403.980304

IPEN (International POPs Elimination Network) (2020, octubre). COVID-19 and Chemicals.IPEN. Recuperadodehttps://ipen.org/site/covid-19-and-chemicals Jouanna, J. y Eijk, P.J. van der (2012). Greek medicine from Hippocrates to Galen: selected papers. Brill.

Kaufmann, S.H.E., Schädlich, S. y Wiegandt, K. (2009). The new plagues: pandemics and poverty in a globalized world. Haus.

Ketcham, C. (2020, 8 de mayo). «Is 5G going to kill us all?». The New Republic. Recuperado de https://newrepublic.com/article/157603/5g-going-kill-us-all Kettler, H.E. (1999). Updating the cost of a new chemical entity. Office of Health Economics.

Kimball, A.M. (2000). Overview and surveillance of emerging infections. Recuperado de https://depts.washington.edu/eminf/2000/emerging/emerg.html

Kime, P. (2020, 16 de junio). «US troops would be among first to get a working COVID-19 vaccine, officials say». Military. Recuperado de https://www. military.com/daily-news/2020/06/16/us-troops-would-be-among-first-getworking-covid-19-vaccine-officials-say.html 
Kirkcaldy, R.D., King, B.A. y Brooks, J.T. (2020). «COVID-19 and postinfection immunity: limited evidence, many remaining questions». The Journal of the American Medical Association. DOI: https://doi.org/10.1001/jama.2020.7869 Kuhn, T.S. (2012). The structure of scientific revolutions. The University of Chicago Press.

Levi-Montalcini, R. y Calissano, P. (2006). «The scientific challenge of the 21stcentury: from a reductionist to a holistic approach via systems biology». BMC Neuroscience,7(1),S1.Recuperadodehttps://doi.org/10.1186/1471-2202-7-S1-S1

Lewis, R. (2016, 2 de septiembre). «Does Chinese civilization come from ancient Egypt?». Foreign Policy. Recuperado de https://foreignpolicy. com/2016/09/02/did-chinese-civilization-come-from-ancient-egyptarcheological-debate-at-heart-of-china-national-identity/

Lietava, J. (1992). «Medicinal plants in a Middle Paleolithic grave Shanidar IV?». Journal of Ethnopharmacology, 35(3), 263-266. DOI: https://doi.org/ 10.1016/0378-8741(92)90023-k

Liu, A. (2020, 1 de abril). «The White House is pushing FDA to clear Fujifilm's Avigan for COVID-19. Should the agency obey?». FiercePharma. Recuperado de https://www.fiercepharma.com/pharma/white-house-asks-fda-toapprove-fujifilm-s-avigan-for-covid-19-should-agency-follow

Loe Fisher, B. (2015, 21 de julio). «21st century cures act eliminates vaccine safety science». NVIC Newsletter. National Vaccine Information Center. Recuperado de http://www.nvic.org/nvic-vaccine-news/july-2015/21st-century-curesact-eliminates-goowd-science.aspx

Lundberg, G. D. (1998). «A comparison of the opinions of experts and readers as to what topics a General Medical Journal (JAMA) should address». JAMA, 280(3), 288. DOI: https://doi.org/10.1001/jama.280.3.288 


\section{GUILLERMO FOLADORI}

Lundh, A., Barbateskovic, M., Hróbjartsson, A. y Gøtzsche, P.C. (2010). «Conflicts of interest at medical journals: the influence of industry-supported randomised trials on journal impact factors and revenue cohort study». PLOS Medicine, 7(10), el000354. DOI: https://doi.org/10.1371/journal.pmed.1000354

Marcum, J.A. (2008). An introductory philosophy of medicine: humanizing modern medicine. Springer. Recuperado de https://b-ok.org/book/740600/fbffed

Martinez, L. (2020, 28 julio). «Study of young Marines in basic training could provide coronavirus clues». ABC7 New York. Recuperado de https://abc7ny. com/6338681/

Marwick, C. (1994). «Advisory group insists on «alternative» voice». The Journal of the American Medical Association, 272(16), 1239. DOI: https://doi. org/10.1001/jama.1994.03520160021009

Mazzocchi, F. (2011). The limits of reductionism in biology: What alternatives? E-Logos/University of Economics Prague. Recuperado de https://nb.vse.cz/ kfil/elogos/science/mazzocchill.pdf

McKeown, T. (1991). The origins of human disease. Blackwell.

Microbiology Society (s.f.). «The history of antibiotics». Microbiology Society. Recuperadodehttps://microbiologysociety.org/members-outreach-resources/ outreach-resources/antibiotics-unearthed/antibiotics-and-antibioticresistance/the-history-of-antibiotics.html

Millman, J. (2014,13 de agosto). «Why the drug industry hasn't come up with an Ebola cure». The Washington Post. Recuperado de http://www.washingtonpost. com/blogs/wonkblog/wp/2014/08/13/why-the-drug-industry-hasnt-come-up -with-an-ebola-cure/

Morse, S.S. (1995). «Factors in the emergence of infectious diseases». Emerging Infectious Diseases, 1(1), 7-15. DOI: https://doi.org/10.3201/eid0101.950102 
OMS (2020, 23 de junio). «Coronavirus. Symptoms». Coronavirus Disease (COVID-2019) Situation Reports. Recuperado de https://www.who.int/western pacific/health -topics

Osorio-de-Castro, C.G.S., Caetano, R.y Pepe, V.L.E.(2015). «The21st century cures act: can the regulatory framework survive the «cures`?». Cadernos de Saúde Pública, 31(9), 1807-1810. DOI: https://doi.org/10.1590/0102-311XPE010915

Passmore, J. (1978). La responsabilidad del hombre frente a la naturaleza. Ecología $y$ tradiciones en Occidente. Alianza.

Patlak, M. (1966). «Book reopened on infectious diseases». FDA Consumer Magazine. Peters, A. (2018). «The global proliferation of high-containment biological laboratories. Understanding the phenomenon and its implications». Revue Scientifique et Technique de l'OIE, 37(3), 857-883. DOI: https://doi.org/10.20506 /37.3.2892

Rawlinson, P. (2017). «Immunity and impunity: corruption in the State-pharma nexus». International Journal for Crime, Justice and Social Democracy, 6(4), 86-99. DOI: https://doi.org/10.5204/ijcjsd.v6i4.447

Sekerka, L.E. y Benishek, L. (2018). «Thick as thieves? Big pharma wields its power with the help of government regulation». Emory Corporate Governance and Accountability Review, 5, 113-141.

Skolnick, A.A. (1994). «FDA petitioned to «stop homeopathy scam». The Journal of the American Medical Association, 272(15), 1154. DOI: https://doi. org/10.1001/jama.1994.03520150020006

Spellberg, B. (2008). «Dr. William H. Stewart: mistaken or maligned?». Clinical Infectious Diseases, 47(2), 294-294. DOI: https://doi.org/10.1086/589579

Stone, J. (2017). «Re: US government website for collecting adverse events after vaccination is inaccessible to most users. Rapid response». British Medical Jour- 


\section{GUILLERMO FOLADORI}

nal, 357. Recuperado de https://www-bmj-com.proxy.lib.sfu.ca/content/357/ bmj.j2449/rr-15

Subbarayappa, B.V. (2001). «The roots of ancient medicine: an historical outline». Journal of Biosciences, 26(2), 135-143. DOI: https://doi.org/10.1007/bf02703637 Tauber, A.I. y Sarkar, S. (1993). «The ideology of the human genome project». Journal of the Royal Society of Medicine, 86(Sept), 537-540.

The New York Times (2020, mayo). «World leaders join to pledge \$8 billion for vaccine, but the U.S. sits out». Recuperado de https://www.nytimes. com/2020/05/04/world/coronavirus-world-cases-deaths.html

U.S. Dep of Health y Human Services (2019, 5 de septiembre). «PREP Act Q\&As». Public Health Emergency. Recuperado de https://www.phe.gov/ Preparedness/legal/prepact/ Pages/prepqa.aspx

Vellingiri, B., Jayaramayya, K., Iyer, M., Narayanasamy, A., Govindasamy, V., Giridharan, B., Ganesan, S., Venugopal, A., Venkatesan, D., Ganesan, H., Rajagopalan, K., Rahman, P.K.S.M., Cho, S.G., Kumar, N.S. y Subramaniam, M. D. (2020). «COVID-19: A promising cure for the global panic». Science of The Total Environment, 725, 138277. DOI: https://doi.org/10.1016/j. scitotenv.2020.138277

Villarreal, L.P. (2009). «The source of self: genetic parasites and the origin of adaptive immunity». Annals of the New York Academy of Sciences, 1178, 194232. DOI: https://doi.org/10.1111/j.1749-6632.2009.05020.x

Wallace, R. (2016). Big farms make big flu: dispatches on influenza, agribusiness, and the nature of science. Monthly Review Press.

Wang, Y., Zhang, D., Du, G., Du, R., Zhao, J., Jin, Y., Fu, S., Gao, L., Cheng, Z., Lu, Q., Hu, Y., Luo, G., Wang, K., Lu, Y., Li, H., Wang, S., Ruan, S., Yang, C., Mei, C., ... Wang, C. (2020). «Remdesivir in adults with severe COVID-19: a 
randomised, double-blind, placebo-controlled, multicentre trial». The Lancet, S0140673620310229. DOI: https://doi.org/10.1016/S0140-6736(20)31022-9 Warren, E. (2016). Senator Warren delivers remarks on the proposed 21st century cures bill. Recuperado de https://www.warren.senate.gov/newsroom/pressreleases/senator-warren-delivers-remarks-on-the-proposed-2lst-century -cures-bill

Wise, R., Hart, T., Cars, O., Streulens, M., Helmuth, R., Huovinen, P. y Sprenger, M. (1998). «Antimicrobial resistance». BMJ, 317(7159), 609-610. DOI: https:// doi.org/10.1136/bmj.317.7159.609

World Health Organisation (2020, 20 de enero). «COVID-19 situation reports. Coronavirus Disease». Recuperado de https://www.who.int/docs/ default-source/coronaviruse/situation-reports/20200121-sitrep-1-2019-ncov. pdf?sfvrsn=20a99c10_4

World Health Organization (1999). «Removing obstacles to healthy development». Recuperado de https://apps.who.int/iris/bitstream/handle/10665/ 65847/WHO_CDS _99.1.pdf?sequence=1\&isAllowed=y

World Health Organization (2020, 17 de enero). «Lack of new antibiotics threatens global efforts to contain drug-resistant infections». Recuperado de https://www.who.int/news-room/detail/17-01-2020-lack-of-newantibiotics-threatens-global-efforts-to-contain-drug-resistant-infections

Wu, X., Nethery, R.C., Sabath, B.M., Braun, D. y Dominici, F. (2020). «Exposure to air pollution and COVID-19 mortality in the United States». Epidemiology. DOI: https://doi.org/10.1101/2020.04.05.20054502 